\title{
Y siempre, por último, con ustedes: la radio. Revisión de la producción bibliográfica y hemerográfica radiofónica en España
}

\author{
Emma Rodero (Universidad Pompeu Fabra) \\ http://dx.doi.org/10.12795/AdMIRA.2009.01.07
}

\section{Introducción: la radio, ¿un medio olvidado?}

Hace aproximadamente un mes que tuve ocasión de compartir unos minutos de charla con el locutor de radio, Luis del Olmo, al que entregué, a modo de detalle por el tiempo dedicado, un libro sobre radio. Su respuesta rápida en ese momento fue: 'ah, pues está muy bien porque como hay tan poco..., siempre es un placer tener en las manos una obra dedicada al medio radiofónico...' También hace unos días que comentaba con una investigadora de radio que debía escribir un artículo en el que se revisara el material radiofónico que se está produciendo en nuestro país y su respuesta igualmente fue bastante automática: 'pues lo tienes difícil, porque de radio, hay bastante poco'.

Sin duda alguna, estos comentarios o impresiones carecen de rigor y están basados únicamente en la experiencia de cada persona, pero no por ello dejan de dibujar bastante a las claras lo que ocurre en este ámbito, lo que es sin duda una constatación que quienes nos dedicamos a la investigación del medio radiofónico conocemos muy de cerca; una realidad que todos podemos detectar incluso de manera intuitiva.

$\mathrm{Y}$ es que en este aspecto, como en muchos otros, la radio rompe con la tendencia general. Aunque se comprueba que "en España (...) hay un exceso de producción bibliográfica y hemerográfica especializada en el análisis de los fenómenos comunicativos y culturales" (Jones, 2006: 448), el ámbito radiofónico continúa siendo una excepción. De hecho, en la revisión bibliográfica que realiza Jones para el año 2004, el apartado radiofónico es de los más escasos, y tan sólo se refieren cinco libros dedicados al medio.

Sin duda, la radio se ha entendido durante mucho tiempo como el medio pobre, al que no sólo se dedican menos estudios sino menos recursos, personal $\mathrm{y}$, en definitiva, atención. La radio es casi siempre la gran olvidada. Y así, proliferan las reflexiones 
sobre el poder de la televisión o el cine, sus usos, su lenguaje. Abundan los estudios sobre la prensa, sus efectos, su historia. En cambio, la bibliografía dedicada al medio, las investigaciones que la convierten en protagonista, son siempre más escasas. "Ciertamente, la bibliografía y hemerografía internacional sobre radio ofrecen un número de títulos muy inferior a los del cine o la prensa, e incluso, pese a su menor antigüedad, a la televisión" (Checa, 2003: 15). Por tanto, dentro de la especialización comunicativa, la radio ofrece un volumen de trabajos que se encuentra bastante por debajo de las investigaciones dedicadas a otros medios.

Y no sólo se trata de que haya pocas investigaciones, libros o artículos sino también de reafirmar que no es un fenómeno nuevo, que aunque pasen los años, la tendencia continua inalterable. Ya en el año 1995, Alonso Erausquin reconocía que la radio "es un medio que no aparece como un elemento puntero en la concitación de estudios relacionados con la comunicación, en España", porque como constata Checa (2003: 15), "las bibliografías de radio son muy escasas en lengua española". En definitiva, la radio ha sido y aún continúa siendo la cenicienta mediática, a pesar de su indiscutible influencia, de ser timón de impulso social, cultural y educativo.

Así pues, desde un punto de vista bibliográfico y hemerográfico, la radio es un ámbito poco trabajado, lo cual se refleja claramente en el escaso volumen de producción que genera este medio. Pero también es cierto que parte de este problema se asienta sobre el déficit existente en investigaciones que se realizan sobre el medio radiofónico. Y no se trata de que no haya investigadores, ni de que éstos no tengan el ánimo, las ganas y la ilusión por hacerlas. Se trata simplemente de que la radio no interesa, se conoce poco y, en consecuencia, resultan escasos los estudios que encuentran financiación para llevarse a cabo. En el día a día, los investigadores sobre el medio radiofónico encuentran no pocas dificultades para conseguir un proyecto de investigación competitivo que tenga por objeto el análisis del medio, especialmente si el estudio no contempla una clara repercusión social, cultural, política o psicológica, es decir, si no se deriva hacia otras ramas del conocimiento. La radio en sí misma, como medio con entidad propia, parece no contar demasiado. 
La raíz de este problema la ha descrito muy acertadamente García (1999), aunque aplicando el diagnóstico a un área más amplia: la comunicación audiovisual, dentro de la cual incluye la radio. García afirma que las dificultades para sacar adelante una investigación en este ámbito se derivan de tres razones:

a) Los proyectos de investigación y las investigaciones mismas realizadas y las tesis doctorales no encuentran su catalogación adecuada en los códigos de la UNESCO.

b) Los proyectos de investigación con contenidos de Comunicación Audiovisual con frecuencia son analizados y valorados por personas no expertas en la materia. Ya que en gran medida la clasificación de la UNESCO rige también en la política educativa, cultural e investigadora.

c) Esta mentalidad lleva a destinar pocos fondos para investigar en Comunicación Social, en general, $\mathrm{y}$, en particular, en Comunicación Audiovisual.

Exactamente esto es lo que ocurre en este ámbito. Primero, el no disponer de un código Unesco provoca que las investigaciones estrictas sobre radio se hayan de dirigir hacia otras especialidades. Esto provoca que, en ocasiones, los investigadores hayan de realizar verdaderas cábalas para lograr incluir una investigación radiofónica en algún ámbito de los propuestos. $\mathrm{Y}$ en muchos casos cuando se consigue, si se permite la expresión, se introduce 'con calzador', porque no hay otro remedio, porque no existe un hueco específico. El resultado inmediato es que estos proyectos son evaluados después por investigadores que ignoran por completo la radio, bajo el más profundo desconocimiento y bajo criterios ajenos al medio radiofónico. Porque si se desconoce la producción científica de un ámbito, resulta difícil evaluar con criterios coherentes y válidos. Más aún, la tendencia es a juzgarlos bajo la perspectiva, teorías y tendencias propias de otras especialidades. Por tanto, como punto tercero, la conclusión final es que se conceden pocos proyectos radiofónicos $\mathrm{y}$, por tanto, se destinan pocos fondos a la investigación de la radio. La solución que García propone ante esta dificultad consiste en incluir, dentro del campo de las Ciencias de la Comunicación, un código específico 
para la radio. Ya hace tiempo que el autor planteaba esta propuesta, que muchos firmaríamos con los ojos cerrados, pero de momento ha sido en vano.

Y es que, sin duda, esta falta de apoyo en la investigación tiene algunas consecuencias añadidas. La primera y más clara es que muchos investigadores del medio optan finalmente por realizar estudios por su cuenta, sin financiación ni reconocimiento, es decir, trabajando 'en la sombra'. Es evidente que las investigaciones son igualmente válidas, pero se encuentran con una dificultad: la menor difusión. Por eso, en la práctica resulta complicado conocer estos estudios, más allá del boca a boca entre los investigadores, de su publicación en revistas de especialidades generales (que no radiofónicas) o de su exposición en congresos, casi siempre de temática diversa, porque los dedicados a la radio son también escasos.

La segunda repercusión es que otros cuantos, ante la falta de producción científica, se dediquen a los aspectos más practicos, es decir, a escribir manuales de soporte para las diferentes asignaturas de radio que se imparten en las Facultades de Comunicación, que hoy por hoy continúan siendo también escasos. Ante la falta de otras oportunidades, no deja de ser una manera más sencilla y efectiva para el investigador de hacer currículum radiofónico $\mathrm{y}$, además, poder contar así con material de ayuda en la práctica diaria docente. Quizá por esta tendencia, autoras como Mata, al analizar el 'saber radiofónico', denuncie que "a la hora del hacer, la radio es artefacto técnico, formatos, mezcla de códigos, normas y criterios de producción. Y eso no ocurre sólo en el campo de la formación universitaria sino en múltiples instancias educativas” (1998: 93).

Sin duda alguna, esta afirmación no se debe ni puede generalizar, pero si en algunos casos se produce, lo que es evidente es que no es un problema de profesores o investigadores del medio (como por otro lado esta misma autora reconoce) sino que viene derivado de las dificultades antes apuntadas. Sin investigación, no se asienta ni evoluciona el saber científico, y éste no puede revertir en la docencia. Pero sin manuales de apoyo a la docencia, o al menos escasos, tampoco surgen oportunidades de descubrir vacíos en determinados temas de investigación o, al menos, la simple ocasión de originar reflexión y material sobre el medio radiofónico. De otra manera, nos quedaríamos sin nada. 
Por otro lado, también resulta importante destacar que muchos de los libros o manuales que se publican sobre el medio radiofónico son fruto de tesis doctorales, gracias a los cuales puede existir su difusión y extender así su conocimiento. Otros son el resultado de algunos estudios que se realizan sin financiación, es decir, por cuenta propia de los autores. Pero aún en el caso de que no fueran consecuencia de una investigación propiamente dicha, el déficit bibliográfico en materia de radio y la necesidad de avanzar en el conocimiento del medio justificarían también su existencia.

Sea como fuere, profesores e investigadores de radio continúan dedicando sus esfuerzos al medio, generando un volumen de producción radiofónica que, teniendo en cuenta estas dificultades, no puede considerarse escaso en términos relativos, aunque lo sea de manera evidente en su comparación con otros ámbitos de la comunicación y con otros medios. Esto es precisamente lo que se pretende comprobar, a partir de este momento, revisando el material radiofónico generado en España desde el año 2006, a partir del cual se puede dibujar un panorama de tendencias en torno al estudio de la radio en nuestro país.

\section{Revisión de la producción bibliográfica y hemerográfica radiofónica}

La revisión que se realizará a continuación se dividirá en ámbitos de especialización radiofónica, intentando recopilar la producción más significativa y con mayor difusión, durante los años 2006, 2007 y 2008. Los ámbitos se han seleccionado en función de las referencias aparecidas durante este tiempo, y son los siguientes: radio genérica, géneros radiofónicos, informativos en radio, radio y nuevas tecnologías, programación y nuevos modelos de radio, lenguaje y narrativa radiofónica, publicidad en radio, radio especializada e historia sobre radio.

\subsection{Radio genérica}

En este apartado más genérico, la revisión incluye dos referencias que pasan por defender una misma idea sobre la radio, aunque planteada desde ángulos diferentes. En el año 2008, Julia González Conde publicaba el libro La radio, el sonido de la supervivencia (Dykinson). Sin duda, un título significativo, que alude a la capacidad del medio para hacer frente y adaptarse a las distintas transformaciones sociales, culturales 
y tecnológicas. Bajo este epígrafe, la autora realiza un recorrido por diversos aspectos relacionados con el medio radiofónico: sus características, el mensaje, la locución, la realización creativa, el guión, el programa en radio o la publicidad.

También bajo esta idea, pero con un planteamiento más crítico, en el año 2007, Chelo Sánchez, junto a esta autora, publican el artículo "Radiografía de la radio en España" (Revista Latina de Comunicación Social), en el que se pretende realizar un diagnóstico de la crisis por la que atraviesa el medio, planteando diez problemas con sus posibles soluciones. La conclusión es optimista, en términos de supervivencia de la radio, pero siempre bajo ciertas condiciones: "Que la radio siga siendo parte del sonido de nuestra vida dependerá, en definitiva, del trabajo de todos nosotros: empresas, anunciantes, profesionales, universitarios, investigadores y oyentes".

\subsection{Géneros radiofónicos}

El apartado de géneros radiofónicos es uno de los que se han desarrollado con mayor profusión, gracias en parte a los grupos de investigación que trabajan en la Universidad de Navarra y en la Universidad San Pablo-CEU de Madrid.

Por un lado, los investigadores de la Universidad de Navarra llevan ya algún tiempo trabajando en el análisis de diferentes géneros radiofónicos, fruto de los cuales se han publicado varias obras y artículos dedicados a la crónica, el reportaje o la tertulia, entre otros. Así, en el año 2008, Pilar Martínez-Costa y Susana Herrera publicaban el libro La crónica radiofónica (IORTV) dedicado a caracterizar este género informativo. Este estudio lo complementan con una serie de artículos publicados en diferentes revistas. El primero de ellos lleva por título "Rasgos diferenciales de la crónica radiofónica" (Comunicación y Pluralismo), en el que se describen los rasgos específicos de este género radiofónico partiendo "del escaso tratamiento que los académicos han dedicado a este género periodístico". Por eso, realizan primero una revisión bibliográfica del tema para después delimitar y explicar sus características diferenciales. Junto a este artículo, también publican el titulado "La crónica radiofónica: entre las rutinas profesionales y la calidad informativa" (Comunicación y Hombre), en el que las autoras pretenden alertar sobre los riesgos que se deberían evitar a la hora de elaborar una crónica radiofónica. 
Además de estas referencias, las autoras también dedican parte de su investigación a la tertulia radiofónica y las publican en el artículo "La tertulia radiofónica como un tipo de conversación coloquial" (Doxa Comunicación), donde se analizan las particularidades de este género de opinión.

El reportaje radiofónico también reúne una serie de referencias a lo largo de estos años, gracias ahora al trabajo de Susana Herrera, que ha abordado este género en varias obras y artículos. En 2008, esta autora publica el libro Cómo elaborar reportajes en radio (La Crujía). En esta obra se parte de la base del importante potencial de un género que, a pesar de ello, continúa siendo muy poco frecuente. Bajo esta idea, el objetivo de este manual es entonces "ayudar a redescubrir un género cuyas posibilidades no pueden ser desestimadas: ni en un medio tan presente como la radio, ni en una época tan compleja como la nuestra. Para ello, esta propuesta aborda el reportaje desde una perspectiva práctica, amena y didáctica e ilustra el contenido con ejemplos reales que certifican la expresividad, el vigor y las posibilidades que admite el género". Este libro se complementa con una serie de artículos de la misma autora dedicados a analizar, ya de forma específica, diferentes aspectos del reportaje radiofónico. En 2007, se publica el artículo "La duración como dimensión temporal en los reportajes radiofónicos" (Área Abierta), esta vez con la colaboración de Crisanto Pérez, que tiene por objetivo estudiar el tratamiento del tiempo en este género. También en la misma revista (Área Abierta), Susana Herrera analiza la estructura del reportaje en radio en un artículo del 2007 que lleva este mismo título. Su objetivo es aquí "describir la función y los requisitos que le corresponden a cada una de estas partes y exponer también los diferentes tipos de aperturas, desarrollos y cierres con los que se pueden construir reportajes en radio". Por último, esta misma autora dedica otra referencia a este género en el artículo titulado "Las cualidades del buen creador de reportajes en radio" (Re-Presentaciones), del año 2006, en el que se marca como objetivo "describir algunas de las cualidades más importantes que pueden ayudar al reportero en el desempeño de su labor".

Pero los géneros radiofónicos son también un ámbito de investigación trabajado en la Universidad San Pablo-CEU, fruto del cual se publica en 2008 el libro titulado Nuevas perspectivas sobre los géneros radiofónicos (Fragua). En esta obra, los profesores de 
radio Julia González, José María Legorburu, Miguel Ángel Nieto y Consuelo Sánchez, bajo la coordinación de Mario Alcudia, repasan desde el género informativo hasta el magacín, pasando por los programas musicales, el género dramático, la información deportiva e incluso, la publicidad como género radiofónico. Y lo hacen bajo una premisa: "los géneros radiofónicos no son ni pueden ser una mera adaptación de los periodísticos, para llegar a la conclusión de que los géneros radiofónicos son categorías de programas que se fundamentan en un acuerdo implícito entre emisores y receptores, conforme a un conjunto de reglas de producción institucionalizadas y reconocibles”.

\subsection{Informativos en radio}

La producción bibliográfica en torno a la radio informativa tiene, en principio, dos referentes en los que se aborda uno de los programas informativos más importantes de la radio: los boletines radiofónicos. Ambas proceden de la Universidad San Pablo CEU y se deben también a Mario Alcudia, quien ha investigado este tema en su tesis doctoral. Como resultado de este estudio, en el año 2006, se publica el libro Boletines horarios radiofónicos (Fragua), en el que se abordan las rutinas productivas y las numerosas variables que inciden en la elaboración y puesta en antena de estos programas informativos, entendidos como uno de los espacios más importantes de cualquier programación radiofónica. Junto a esta referencia, el mismo autor publica también en 2006 el artículo "Misión de los boletines horarios en la radio generalista" (Actas del Congreso Internacional Lusocom), estudio en el que se analizan los boletines de las cinco emisoras de radio generalistas en España, concibiéndolos también como "el esqueleto en el que se cimienta la programación radiofónica”. Por último, de manera más genérica, este mismo autor edita un cuaderno de trabajo titulado "La radio, entre la información y la opinión" (CEU Ediciones) que recoge la aportación de varios autores sobre la información nocturna en radio, la opinión y el análisis de la actualidad, los programas informativos en la radio generalista, el silencio como componente semántico en la radio y la información especializada en las cadenas estatales con programación generalista.

Junto a estos estudios, los años 2006, 2007 y 2008 aportan otras tres referencias que pueden considerarse innovadoras desde el punto de vista de la concepción de la 
información radiofónica. La primera de ellas, viene de la Universidad de La Laguna y es el libro titulado Radio e información: elementos para el análisis de los mensajes radiofónicos, de Rodrigo Fidel Rodríguez. La obra examina los elementos que explican la lógica que subyace a la producción de mensajes en el medio radiofónico. Entiende que "el análisis de los mensajes de radio no puede limitarse al estudio de cada uno de ellos como unidades aisladas y autosuficientes. Al contrario, deben ser observados como eslabones del continuum sonoro que constituye el discurso radiofónico para comprenderlos".

La segunda aportación se debe a Silvia Jiménez y lleva por título La creatividad en los informativos radiofónicos (Fragua). Este libro es el resultado de la investigación realizada sobre el tema en su tesis doctoral. Se trata de un estudio arriesgado por cuanto une ambos conceptos, creatividad e información, defendiendo la idea de que "la comunicación radiofónica creativa es una demanda de la mayor parte de los especialistas para no desaprovechar el presente, pero, sobre todo, para afrontar el futuro". En estas páginas analiza algunas variables en los informativos radiofónicos que permiten concluir que la creatividad en estos programas está muy por debajo de lo deseado.

La tercera referencia, aunque no estrictamente dedicada a la radio, es el libro de Michel D. Suárez que lleva por título Dramaturgia audiovisual. Guión y estructuras de informativos en radio y televisión (Comunicación Social). Resulta también una concepción novedosa, por cuanto busca aplicar esquemas propios de la dramaturgia a la información radiofónica. "Conceptos como clímax, conflicto o progresión dramática constituyen verdaderos anatemas para quienes se resisten a la aplicación de la estructura dramática a la información periodística (...). Ciertamente, aislarse de este debate provoca, entre otras cosas, dos terribles consecuencias. La primera es que los informativos de radio y televisión corren el riesgo de convertirse en las 'cenicientas morfológicas' de los medios, mientras la innovación formal avanza en el resto de la programación. La segunda consecuencia se relaciona con el axioma que bautiza la realidad como un mundo mucho más rico que el de la ficción. Negar este presupuesto es mirar hacia otro lado". 
Unida a estas aportaciones, el año 2008 también nos trae una obra que, aunque no se dedica tampoco en exclusiva al medio radiofónico, merece también una mención. Es el libro titulado Claves para elaborar la información en radio y televisión (IORTV), de Miguel Ángel Ortiz, una obra práctica en la que, como su propio nombre indica, el autor explica los procedimientos para elaborar la información en radio. Este apartado se completa también con el artículo de Pilar Martínez-Costa y Susana Herrera "Radiografía del prime time informativo de la radio española" (Comunicación), donde se describen las principales características de la radio en las horas de máxima audiencia.

Dentro del estudio de la información radiofónica, pero con una aplicación diferente, el equipo de investigación de radio de la Universidad Pontificia de Salamanca trabaja desde algunos años en el análisis de la cobertura informativa realizada por diferentes emisoras durante los atentados del 11 de marzo en Madrid. Como resultado de ellos, se han publicado ya tres referencias. La primera de ellas, presentada en el Congreso Internacional Investigar la Comunicación celebrado en Santiago de Compostela en enero de 2008, lleva por título "El tratamiento de las fuentes en el discurso informativo de la Cadena Ser durante los atentados terroristas del 11 de marzo en Madrid (desde el 11 al 14 de marzo)”. En él, Ana Tamarit y Aurora Pérez, junto a esta autora, realizan un análisis de las fuentes citadas en los informativos de esta emisora durante los atentados, concluyendo que son las oficiales y, especialmente las del gobierno, las más frecuentes. Unido a este estudio, las autoras presentan también al $X$ Foro Universitario de Investigación en Comunicación. La comunicación: Memoria, Historia y Modelos la investigación relativa a los géneros radiofónicos que se emplean durante estos mismos días, bajo el título "Los géneros radiofónicos empleados en los programas informativos de la Cadena Ser durante los atentados terroristas del 11 de marzo en Madrid (desde el 11 al 14 de marzo de 2004)". Por último, se publicará el artículo titulado "El atentado del 11 de marzo de 2004 en la Cadena Ser desde la teoría del framing”, cuyo objetivo es determinar cuál es el encuadre dominante bajo el que se enmarca la información radiofónica de esta emisora durante los días del atentado. La principal conclusión es que la información se ofrece desde la perspectiva de la responsabilidad, es decir, desde la autoría del atentado. 
Por último, dedicado en este caso a la redacción y la locución, también se publica durante este período, en el año 2006, el libro Redacción y locución en la información audiovisual: escribir noticias para la radio y la televisión (Universidad del País Vasco), de José Larrañaga, que se edita con el objetivo claro de servir de instrumento para lograr un nivel de capacitación en la escritura y la locución de las noticias en estos dos medios.

\subsection{Radio y nuevas tecnologías}

Sin duda alguna, como por otro lado resulta lógico, el apartado de nuevas tecnologías es uno de los más prolíficos en cuanto a producción radiofónica. Ya el año 2006, se inicia con un artículo, de Mónica López, titulado "La radio por Internet: una radio sin fronteras" (Razón y Palabra). En él, se analizan las características de la radio on line: el feedback, los nuevos mensajes, el espacio sin jerarquía, nuevos formatos $\mathrm{y}$ programaciones, nuevas tecnologías y oyentes y la música en Internet.

Pero, sin duda, una de las aportaciones más importantes en lo que se refiere a la publicación de libros es la obra de Mariano Cebrián Herreros La radio en Internet (La Crujía), editado en 2008. El autor divide la obra en tres partes. En la primera, se centra “en el análisis de las diversas peculiaridades y aportaciones de la ciberradio, situándola en el conjunto de los cibermedios, y profundiza en el nuevo modelo comunicativo interactivo que desarrolla, en la nueva expresividad sonora, en los géneros específicos y en las transformaciones de la programación, programas y fragmentaciones. La segunda parte se dedica al examen de las extensiones que van naciendo de la ciberradio como la web 2.0 o redes sociales de audio, la sindicación mediante la RSS y los intercambios de audios mediante las redes P2P, las webs de audio, el podcasting, los blogs y audioblogs y la radio móvil. El libro se cierra con un capítulo en el que se establece el ecosistema político, social, económico y cultural de interrelaciones de la ciberradio".

El resto de las aportaciones de este ámbito provienen de dos congresos. En primer lugar, dentro del Congreso Internacional Investigar la Comunicación, se presentan dos comunicaciones. La primera de ellas se encuentra a caballo entre la programación y las nuevas tecnologías y se debe a Josep María Martí. Lleva por título "Factores que 
inciden en las transformaciones de la radio especializada en el actual contexto digital. Del modelo Radio 1.0 al 2.0". En este estudio, el autor intenta "formular un reportorio de parámetros necesarios para llevar a cabo la investigación de los factores que definen un cambio de etapa en la evolución del medio radiofónico", en un marco en que "la oferta programàtica especializada y el consumo radiofónico están iniciando un proceso de transformación como consecuencia del aumento de soportes de difusión y básicamente los digitales: Internet, telefonia móvil, satélite". Se trata de una de las investigaciones realizadas desde el Observatorio de la Radio de Cataluña que en estos momentos se encuentra trabajando en dos ámbitos principales: "Estudio sobre la Radio y los Jóvenes. Problemática actual y tendencias de futuro" y "Estudio sobre el futuro de la difusión radiofónica en soportes digitales", además del habitual Informe sobre la Radio en Cataluña.

La segunda de ellas es la presentada por un grupo de profesores de la Universidad de Navarra: Pilar Martínez-Costa, Avelino Amoedo y Elsa Moreno en la comunicación titulada "Estrategias de comunicación de las cadenas generalistas españolas en la red: anàlisis comparativo de www.cadenaser.com, www.cope.es, www.ondacero.es, www.puntoradio.com y www.rne.es/programas/radiouno en las temporadas 2006-07 y 2007-08\%. En este caso, los autores ofrecen un estudio de las estrategias de comunicación de las cadenas generalistas españolas en la red con el fin de determinar "la originalidad de la oferta de contenidos que proponen en este soporte, así como el aprovechamiento de las posibilidades que ofrece. Este análisis pretende avanzar en otra línea de investigación en la que vienen trabajando los autores, y que aborda las estrategias de comunicación de las cadenas radiofónicas españolas en Internet (generalistas y musicales)".

Las otras aportaciones son comunicaciones presentadas en otro encuentro importante celebrado en este período: el Congreso Internacional de ECREA. Aquí se recogen cuatro referencias. La primera de ellas es fruto de la línea de investigación que hemos comentado en la Universidad de Navarra; por tanto, tiene a los mismos autores como protagonistas, aunque en este caso encabezados por Elsa Moreno, junto a Avelino Amoedo y Pilar Martínez-Costa. La comunicación se titula "Radio y web: estrategias de 
comunicación de las emisoras de radio españolas en la web (2006-2008)". En este estudio, se analizan los sitios web de las principales cadenas de radio españolas, tratando de determinar el grado de originalidad de los contenidos y servicios que ofrecen, así como las estrategias de comunicación que emplean.

Próxima a este contenido está también la comunicación titulada "RadioNet 2.0: penetración de los servicios de radio online en España”, presentada por Manuel y Felipe Gértrudix Barrio. La investigación pretende estudiar la diferencia que existe entre la evolución de los crecientes servicios que las emisoras ofrecen en la web y el estado de la demanda. Por tanto, su interés está en conocer la penetración social y el uso que se hace de estos nuevos servicios de radio.

También la web 2.0 es objeto de otra comunicación presentada a este congreso por Susana Herrera y José Luis Requejo, bajo el título "Incluyendo recursos de participación Web 2.0 en los portales de radio españoles", en el que se analizan las nuevas posibilidades de participación de la audiencia en el marco de desarrollo de la web 2.0 y cómo las utilizan las emisoras de radio españolas.

Por último, en la comunicación de David Fernández y Montse Bonet, titulada "Más allá del DAB: otra radio digital es posible", los autores analizan las estrategias multicasting de los principales operadores del mercado radiofónico catalán, deteniéndose en cuatro frentes: la propiedad, la ampliación de la red, el formato de programación y su papel como compañías independientes o integrantes de un grupo multimedia.

\subsection{Programación y nuevos modelos de radio}

También se pueden encontrar varias referencias dentro del apartado de programación o nuevos modelos de radio. Precisamente este es el título del libro publicado por Mariano Cebrían Herreros en el año 2007: Modelos de radio, desarrollos e innovaciones: del diálogo y participación a la interactividad (Fragua), donde aborda un medio en permanente transformación, analizando los cambios relevantes de los últimos años y aportando algunas tendencias a partir de la realidad actual. 
Las referencias bibliográficas dentro de este apartado se completan con la obra de Iván Tenorio: La nueva radio: manual completo del radiofonista moderno (Marcombo). Como el anterior, es un libro de referencia que "entiende la Nueva Radio como el resultado del trabajo obtenido por el uso del código propio del lenguaje radiofónico, sumado a las posibilidades generadas por la sinergia con las denominadas nuevas tecnologías." Para ello, realiza un análisis del sector radiofónico, una breve historia de la radio, el lenguaje radiofónico y a la programación y aporta, además, una selección de programas informáticos de libre uso para realizar montajes radiofónicos o automatizar una emisora de radio las 24 horas.

A estas dos referencias, se puede añadir el artículo "En busca de la nueva radio" (Revista del CES Felipe II), que Carlos Hurtado publica en 2007. En él, se analizan las nuevas formas de hacer radio en el nuevo entorno, la radio digitalizada: radio con imágenes, radio espacial, radio interactiva y radio individual, bajo una mirada optimista donde "la radio, experta en evolución, se prepara para el nuevo reto audiovisual, con presencia en todas las formas comunicativas posibles, individuales o grupales, e incluso globales. Mucho donde elegir. La radio está en forma", concluye el autor.

Dentro del ámbito estricto de la programación, se pueden destacar dos referencias que se presentan en 2008 en sendos congresos y que provienen de la Universidad Autónoma de Barcelona, centro donde existe un grupo de investigación que habitualmente realiza estudios sobre este ámbito. La primera de ellas, presentada en el Congreso Internacional Investigar la Comunicación, es un estudio llevado a cabo por María Gutiérrez que lleva por título "La singularidad frente a la homogeneidad en la radio convencional española. Las cadenas de ámbito de difusión estatal”. Frente a la homogeneización de la oferta radiofónica, el principal objetivo de la autora es “determinar los perfiles particulares y observar cómo éstos se plantean y desarrollan en las parrillas de programación de las emisoras con un ámbito de cobertura estatal”. El análisis realizado en este estudio permite también "comprobar la existencia o no de estrategias o políticas programáticas destinadas a destacar lo particular frente a lo general, dado el tratamiento que dichos productos reciban en la difusión convencional y/o on line". 
La segunda referencia es una comunicación presentada al Congreso Internacional de ECREA, por Josep María Martí y Belén Monclús, bajo el marco antes mencionado del Observatorio de la Radio de Cataluña, que lleva por título "La construcción de la radio musical 2.0 dentro de la web. Los adolescentes están transformando el formato de música convencional en radio". El estudio parte de la crisis por la que atraviesa el formato convencional de música en radio, reflejado especialmente en el descenso de audiencia, y analiza entonces las nuevas tendencias que llegan desde Internet. Finalmente proponen que el formato convencional de música en radio tenga en cuenta, entre otros aspectos, el fenómeno sociológico que implica la personalización de las tendencias musicales así como la necesidad de reconsiderar la programación introduciendo formatos que sean compatibles con un consumo fragmentado $y$ multisoporte.

Por último, dentro de este apartado, cabe resaltar el estudio que Pilar Martínez-Costa y Susana Herrera realizan, en este caso, aplicado a la participación de los oyentes en la radio, fruto del cual publican en el año 2007 el artículo titulado "La participación de los oyentes en la programación de la radio española: estudio del caso de RNE, Radio1" (Comunicación y Sociedad). Se trata pues de otra línea de investigación clara especialmente de una de las autoras, Susana Herrera, que en ese mismo año publica el artículo "La radio española y su apuesta por las nuevas modalidades para la participación de los oyentes" (Congreso La ética y el derecho de la información en los tiempos del postperiodismo). Aquí, la autora analiza las nuevas modalidades participativas que ha generado la aparición de Internet. Los resultados de la investigación apuntan a que son las emisoras especializadas en música y dirigidas a un público joven las en mayor medida emplean estas nuevas modalidades.

\subsection{Lenguaje y narrativa radiofónica}

Este apartado aglutina aquellas referencias que tienen que ver directamente con el análisis de los elementos del lenguaje radiofónico o la narrativa radiofónica, entendida en sentido estricto, es decir, circunscrita al ámbito de la ficción. 
En lo referente al lenguaje radiofónico, el año 2006 aporta una importante referencia en el libro de Julio Arce titulado Música y radiodifusión: los primeros años (1923-1936), (Instituto Complutense de Ciencias Musicales). El autor justifica la obra en la escasez de estudios que se aplican a la relación, más que evidente, que existe entre la música y el medio radiofónico. Por tanto, su propósito es "cubrir un hueco en la historiografía de la música española reciente desde una perspectiva global, que incluye la producción, la tecnología, las audiencias, el lenguaje radiofónico y la difusión de los distintos tipos de música".

Junto a esta obra, otra interesante aportación al estudio del lenguaje radiofónico, en este caso del 2007, es la tesis doctoral de Eva Comas titulada "Els recursos sonors en els informatius radiofònics. Anàlisi dels recursos sonors en els relats periodístics dels informatius de migdia de Catalunya Informació, Catalunya Ràdio, COM Ràdio, COPE Catalunya, Ona Catalana, Onda Rambla, Ràdio 4 i SER Catalunya del 16 i 17 de juliol del 2001 i del 5 i 6 d'abril de 2004". El objetivo de esta investigación es analizar los recursos sonoros que se emplean en los informativos radiofónicos para ilustrar las noticias. Su principal conclusión es que, “a excepción de los cortes de voz, los periodistas radiofónicos de las emisoras catalanas usan muy poco los recursos sonoros en el momento de construir sus narraciones sobre la realidad".

Dentro del lenguaje radiofónico, la locución cuenta con algunas referencias importantes. En el año 2007, se publica el artículo titulado "Caracterización de una correcta locución en los medios audiovisuales" (Estudios del Mensaje Periodístico), de esta misma autora. Se trata de un compendio de recomendaciones y análisis de defectos en torno a la locución informativa en radio y televisión, basada en los datos obtenidos en doce diferentes investigaciones realizadas en este campo. Precisamente, la Universidad del País Vasco es una de las más activas en este aspecto, junto a la Pompeu Fabra y a la Autónoma de Barcelona (a través del Laboratorio de Voz Laicom dirigido por Ángel Rodríguez Bravo). En la Universidad del País Vasco, Gotxon Toral se encuentra iniciando una investigación sobre la eficacia de la Técnica de Visualización para mejorar la desenvoltura de los locutores ante la cámara y el micrófono. Anteriormente ya se habían presentado dos estudios: "Influencia de la autoimagen del comunicador en 
la locución radio televisiva" (2004-2006) y "Eficacia del biofeedback para afrontar el miedo escénico en situaciones de locución radiotelevisiva" (2006-2008). Estas investigaciones se completan con tres artículos. El primero de ellos, de Gotxon Toral, se titula "Preparer les voix du futur" (Médiatiques.Recit et Societé). Los otros dos se realizan en colaboración con Murelaga y Vidales: "Comunicación emocional y miedo escénico en radio y televisión" (Signo y Pensamiento) y "Autoconfianza y miedo escénico en radio y televisión" (Uztaro).

Dentro del apartado de narrativa radiofónica, entendida como ficción, se pueden encontrar en estos años varias referencias, si bien de índole diversa. En lo que respecta estrictamente al análisis del discurso, en 2006, Xosé Soengas publica el artículo titulado "El discurso radiofónico. Particularidades de la narración sonora" (Prisma). En este artículo, el autor analiza dos modalidades discursivas en el medio radiofónico: la narración improvisada o elaborada, para después centrarse especialmente en la elaborada, desgranando sus principales características y normas y diferenciando las particularidades del discurso informativo frente al dramático. Un año más tarde, si bien enfocado desde la perspectiva del radio arte, Ricardo Haye publica el artículo titulado "La radio y los movimientos artísticos. De la dictadura de la realidad al debilitamiento expresivo" (Telos), donde aboga por "reinventar la radio a través de la construcción de nuevas poéticas sonoras capaces de enriquecer su expresividad".

El año 2008 también aporta dos referencias, circunscritas estrictamente a la ficción radiofónica y con carácter más histórico. Ambas, además, tienen en común que son fruto de las investigaciones realizadas por las autoras dentro de sus respectivas tesis doctorales y que se presentaron en el mismo foro: el Congreso Internacional Investigar la Comunicación. La primera de ellas se debe a Elisa Arias, de la Universidad Pontificia de Salamanca, y lleva por título "El serial radiofónico como producto de creación: análisis de la estructura del primer capítulo de 'Ama Rosa'”. En este caso, la autora parte de la concepción del serial como uno de los géneros con mayor potencial expresivo del medio radiofónico. Y así, bajo este marco, analiza la estructura narrativa del primer capítulo de uno de los seriales con más éxito en la historia de la radiodifusión española: Ama Rosa. En esta misma línea, la autora presentó también una comunicación 
en las I Jornadas Internacionales de Narrativa Radiofónica, que organizó la Universidad Completense de Madrid en mayo de 2008, titulada "Análisis del lenguaje radiofónico en La saga de los porretas”.

Precisamente la organización de estas primeras jornadas de narrativa corrió a cargo de otra de las investigadoras de este ámbito: Gemma Ventín. Esta autora presentó en el Congreso Internacional Investigar la Comunicación la comunicación titulada "La primera novela escrita para la radio: enero de 1926". También esta autora parte de la misma idea: la alta carga expresiva que, desde el punto de vista narrativo, poseen todos los formatos dramatizados. Razón en la cual la autora justifica el estudio de la primera radionovela difundida por las ondas en España: La muerte de Mr Stay. Su objetivo consiste entonces en "realizar una aproximación a las características discursivas en los inicios de la radiodifusión, y ver cómo se enfrentaban los profesionales de entonces al reto de radiar una novela por la radio (...): la creación de imágenes sonoras y de un espacio virtual, es decir, al desarrollo de los planos sonoros, a la adaptación de un diálogo apropiado para un nuevo medio que acaba de dar sus primeros pasos, etc".

A estas dos publicaciones, se añade la presentada en el Congreso Internacional de ECREA de 2008, titulada "Punto de escucha en una ficción radiofónica: el eterno problema", de esta autora, en la que se analizan treinta historias de ficción en radio con el objetivo de determinar los principales errores que se comenten a la hora de localizar de forma adecuada el denominado punto de escucha.

A pesar de no contar aún en esta fecha con aportaciones concretas o publicadas, lo cierto es que el ámbito de la narrativa de ficción radiofónica es un aspecto que se investiga en varias Facultades de Comunicación: desde la Universidad de Sevilla, pasando por el País Vasco, la Universidad Pompeu Fabra, la Universidad de Santiago de Compostela, la Universidad Pontificia de Salamanca, la Universidad Complutense de Madrid o la Autónoma de Barcelona, por poner sólo algunos ejemplos. Fruto de estos estudios saldrán próximamente a la luz dos obras sobre Narrativa Radiofónica, una que se debe a Virginia Guarinos (Síntesis) y otra de esta autora junto con Xosé Soengas. Se está preparando también una investigación sobre radioteatro en la Universidad Camilo 
José Cela. Junto a ello, en la Universidad Pompeu Fabra se trabaja especialmente en la influencia de las nuevas tecnologías en la estética de los contenidos radiofónicos así como en las características acusmáticas del medio.

\subsection{Publicidad radiofónica}

Otro campo importante donde parece estar evolucionando la producción radiofónica es, sin duda, el publicitario, gracias también a que existen grupos de investigación activos en la Universidad Autónoma de Barcelona (Publirradio), en la Universidad de Vigo, en la Universidad Autónoma de Madrid y en la Universidad Pompeu Fabra, por poner algunos ejemplos.

Fruto de algunos de estos estudios surgen en el año 2006 dos libros dedicados a la publicidad radiofónica. El primero de ellos, del que es autora Isabel Hernández Toribio, se titula El poder de la palabra en la publicidad de radio (Octaedro). Se trata de una obra que intenta dar respuesta a una serie de interrogantes a la hora de elaborar la publicidad en radio: “¿cómo se lleva a cabo la personalización del mensaje para conseguir la persuasión del oyente, qué características del soporte material de transmisión otorgan más nítidamente especificidad al discurso publicitario de la radio; cuáles son las funciones que pueden atribuirse a la presencia de la música, el paralenguaje y otros efectos sonoros en la configuración global del mensaje; bajo qué formatos se presentan los mensajes publicitarios en la radio; qué valores implícitos, de diversa naturaleza, sustentan esta particular práctica discursiva, y en función de qué finalidad/es surge este perfecto entramado".

Junto a esta referencia, también en el mismo año, el grupo de investigación de Publirradio (Armand Balsebre, José María Ricarte, Juan José Perona, Mari Luz Barbeito, David Roca y Anna Fajula) edita la obra Los mitos de la publicidad radiofónica: estrategias de la comunicación publicitaria en la radio española (Cátedra). En él, los autores tratan de dar respuesta a un interrogante: ¿Por qué la radio es un medio publicitariamente menor, inexistente para muchos grandes anunciantes? Para ello, realizan "una radiografía sobre los mitos que limitan, todavía hoy, el mundo 
de la publicidad radiofónica, haciéndose eco al mismo tiempo de la conciencia crítica que anida en el sector".

Un planteamiento de la publicidad totalmente diferente, en este caso, desde la vertiente de la producción, aunque con la misma base de partida, es decir, la crisis de la publicidad en radio, es el que aborda la obra de Manuel Sánchez, titulada Sonido envolvente 5.1.: una posible solución a la crisis publicitaria radiofónica en España (Dykinson), fruto de su tesis doctoral. El autor plantea en estas páginas una posible solución a esta situación de crisis en la producción publicitaria española actual. Solución que, debidamente argumentada y justificada, viene de la mano de la aplicación de la tecnología de Sonido Envolvente 5.1., para "lograr mensajes más expresivos, originales, comunicativos y rentables".

Precisamente en esta misma línea, que pone de relieve la crisis publicitaria aplicada a la radio, se publica en 2008 el artículo, de esta autora, titulado "Publicidad sí, pero no radiofónica" (Área Abierta). A lo largo de estas páginas, la autora propone una reflexión sobre los problemas detectados en este ámbito en un intento por encontrar soluciones que ayuden a superar el actual estancamiento de la publicidad radiofónica.

El resto de las referencias encontradas sobre este ámbito se presentaron, en 2008, al Congreso Internacional Investigar la Comunicación. La primera comunicación representa precisamente una revisión de la investigación realizada en la Universidad de Vigo sobre publicidad. Lleva por título "10 años de investigación en radio desde la Universidad de Vigo. De lo local a lo universal" y las autoras son Aurora García y Mercedes Román. A través de las investigaciones desarrolladas, y los estudios publicados, las autoras destacan los temas, métodos y herramientas utilizadas de manera preferente en la investigación de esta materia y que están dando resultados positivos.

La segunda comunicación tiene por objeto de estudio uno de los géneros más importantes de la publicidad radiofónica: la cuña. Lleva por título "La radio y su publicidad. Creación, estructura y formatos de la cuña radiofónica” y sus autores son Ana Sebastián y Luis Rodrigo, de la Universidad de Valladolid; un centro del que han 
surgido también otras investigaciones en este ámbito. Empleando la técnica de la entrevista personal a profesionales del mundo radiofónico, los autores intentan "ampliar y profundizar en la creación y realización de cuñas radiofónicas, analizando los géneros y tipología de formatos de este género".

\subsection{Radio especializada}

El apartado de radio especializada, en este caso por ámbito geográfico, aporta en principio tres referencias que analizan diferentes aspectos de la radio en Iberoamérica, Cataluña y el País Vasco.

La primera de ellas es la obra coordinada por Arturo Merayo titulada La radio en Iberoamérica. Evolución, diagnóstico y prospectiva, (Comunicación Social) "que reúne las aportaciones de más de veinte estudiosos y profesionales del medio de toda Iberoamérica con el objetivo de dotar a las instituciones académicas españolas, iberoamericanas y anglosajonas, de un texto de referencia básico para conocer cómo son y qué se hace en la radio de estos países". Se trata, por tanto, de un libro que viene a paliar un claro définit: la escasez de obras que realicen un análisis global de la radio en Iberoamérica, "país por país y repasando no sólo su historia sino su evolución jurídica, su estructura empresarial, sus audiencias y las tendencias de futuro".

La segunda de ellas es el libro publicado en 2007 por Daniel Casals y que se lleva por título Radio en català: contribució de Catalunya Ràdio (Abadia de Montserrat). Se trata de una obra fruto de su tesis doctoral, en la que estudia las características principales del lenguaje radiofónico catalán, analizando el comportamiento de seis variables sintácticas en un corpus de noticias de Catalunya Ràdio. Los resultados del estudio le conducen a realizar una propuesta de criterios de redacción de noticias radiofónicas, destinadas a los periodistas, para reforzar sus habilidades expresivas.

Por último, la tercera aportación se presentó en el Congreso Internacional Investigar la Comunicación (2008). Se trata de la comunicación titulada "Las emisoras libres, 
asociativas y comunitarias del País Vasco en el dial de Internet. Las nuevas tecnologías al servicio de un espacio radiofónico sin cadenas", de Arantza Gutierrez. En este artículo parte de la tesis de que "las emisoras libres y comunitarias del País Vasco han encontrado en las nuevas tecnologías y, sobre todo, en Internet una vía para revitalizar un espacio comunicativo alternativo en un dial dominado por las grandes cadenas privadas y públicas". Para reforzar esta tesis, realiza un estudio de las propuestas de estas emisoras en Internet.

Junto a ellas, aunque de diferente índole, existen dos referencias que añadir en este ámbito: el artículo de esta autora titulado "Educar a través de la radio" (Signo y Pensamiento), donde se presenta la radio como una fuente propicia para cumplir con el propósito de recuperar y potenciar la cultura auditiva, diluida hoy por hoy, dentro de la audiovisual, y una apuesta por la radio infantil de la mano de Chelo Sánchez y Aurora Pérez presentada en el XXIII Congreso Internacional Comunicación: Excelencia e Innovación en la Comunicación, de Pamplona (2009) titulada "Busquemos el flautista de Hamelín que devuelva la radio a los niños"

\subsection{Historia sobre la radio}

Las referencias históricas en torno a la radio han sido, durante este período, más escasas que en otros ámbitos y, de hecho, sólo se han podido recuperar tres aportaciones. La primera de ellas es el libro, del año 2007, titulado La Radio en España (1896-1977): una historia documental (Taurus), de Ángel Faus, en el que el autor ofrece referencias y documentos, desconocidos hasta el momento, y muy reveladores. De hecho, una de las aportaciones principales de esta obra consiste en afirmar que el inventor de la radio fue el español Julio Cervera Baviera y no Marconi, tal como se creía hasta ahora, y que la primera emisora de radio española fue en realidad Radio Madrid, impulsada por una asociación de comerciantes de la ciudad, que estuvo funcionado a comienzos 1924.

La segunda contribución es también un libro, en este caso, de Joan Munsó titulado Tiempo de radio (La Esfera de los Libros), que se publica en el año 2006. En esta obra, el autor realiza un amplio recorrido por la historia de una singular e irrepetible cadena 
de radio, Cadena Catalana, que logró captar los instantes más relevantes de la transisión política. Por eso, el libro representa también un repaso de nuestra historia más reciente.

La última de ellas es también un libro, de 2006, que si bien está dedicado también a la televisión, merece aquí su mención por la parte radiofónica. Se trata de la obra titulada Radio y televisión en España: historia de una asignatura pendiente de la democracia (Gedisa), de Enrique Bustamante, donde se analiza la evolución de ambos medios en el contexto político, económico y cultural de cada etapa, desde sus orígenes hasta la actualidad reciente. Esto supone en total más de ochenta años en el caso de la radio.

\section{Conclusiones: un ámbito activo}

Éstas son pues las referencias más significativas en materia radiofónica, recogidas durante estos años en España, si bien se es consciente de que no las únicas, por razón de tiempo y espacio. A pesar de que no están todas, durante estos tres años de revisión se han podido contabilizar 23 libros y casi 40 artículos dedicados al medio radiofónico. Los ámbitos de especialización en los que existen más referencias, por tanto, en aquellos en los que se puede deducir que se realiza más investigación son los géneros radiofónicos y la información en radio, seguidos de cerca por los estudios relativos a las nuevas tecnologías aplicadas al medio. En cambio, donde menos producción se detecta es en la historia de la radio y en la radio especializada por ámbitos geográficos, junto a las referencias de obras o artículos genéricos sobre el medio.

Este conjunto de datos, en definitiva, permite vislumbrar un futuro prometedor para el medio radiofónico, por cuanto revela que existe cierto nivel de actividad radiofónica y que desde varios frentes, desde varias Facultades de Comunicación, se continúa trabajando muy activamente por la radio. Por tanto, a pesar de que son referencias escasas en términos absolutos, si se comparan con el volumen bibliográfico y hemerográfico destinado a otros medios de comunicación, lo cierto es que no pueden calificarse en modo alguno como datos negativos, si se tienen en cuenta las dificultades apuntadas al comienzo de estas páginas. Muy al contrario, son resultados para la esperanza que animan a seguir trabajando en el medio olvidado. Quizá de esta manera, 
en un posterior diagnóstico dentro de un tiempo, se logre inventir la tendencia de la que habla Mata:

En términos generales - y como muchos docentes de esa especialidad reconocen- la enseñanza de la radio no parte de una interrogación sobre el quehacer radiofónico que permita su intelección como práctica social posibilitando, así, la necesaria articulación entre el pensar y el hacer en torno a los distintos aspectos que la constituyen: desde su materialidad técnica hasta su dimensión simbólica (Mata, 1998: 94).

Sin duda, la voluntad y el esfuerzo de los investigadores de radio continuará estando presente para lograr este objetivo, pero necesita de la ayuda de otros sectores, especialmente desde el frente de la investigación, que reconozcan de una vez por todas el papel y la influencia esencial del medio de la imaginación, de la radio.

\section{Bibliografía}

\subsection{Libros}

ALCUDIA, Mario: Boletines horarios radiofónicos. Fragua, Madrid, 2006.

ALCUDIA, Mario (coord.): Nuevas perspectivas sobre los géneros radiofónicos. Fragua, Madrid, 2008.

ALCUDIA, Mario (ed.): La radio, entre la información y la opinión. Cuadernos de Comunicación Audiovisual y Nuevas Tecnologías, CEU Ediciones, Madrid, 2008.

ARCE, Julio: Música y radiodifusión: los primeros años (1923-1936). Instituto Complutense de Ciencias Musicales, Madrid, 2006.

BUSTAMANTE, Enrique: Radio y televisión en España: historia de una asignatura pendiente de la democracia. Gedisa, Madrid, 2006.

CASALS, Daniel: Radio en català: contribució de Catalunya Ràdio. Publications de l’Abadia de Montserrat, Barcelona, 2007.

CEBRIÁN, Mariano: La radio en Internet. La Crujía, Argentina, 2008.

CEBRIÁN, Mariano: Modelos de radio, desarrollos e innovaciones: del diálogo y participación a la interactividad. Fragua, Madrid, 2007. 
CHECA GODOY, Antonio: Fuentes sobre radio. Un siglo de bibliografia internacional. Mergablum, Sevilla, 2003.

FAUS, Ángel: La Radio en España (1896-1977): una historia documental. Taurus, Madrid, 2007.

GÓNZALEZ CONDE, Julia: La Radio. El sonido de la supervivencia. Dykinson, Madrid, 2008.

HERNÁNDEZ TORIBIO, Isabel: El poder de la palabra en la publicidad de radio. Octaedro, Barcelona, 2006.

HERRERA, Susana: Cómo elaborar reportajes en radio. La Crujía, Argentina, 2008.

JIMÉNEZ, Silvia: La creatividad en los informativos radiofónicos. Fragua, Madrid, 2008.

LARRAÑAGA, José: Redacción y locución en la información audiovisual: escribir noticias para la radio y la televisión. Universidad del País Vasco, Bilbao, 2006.

MARTÍNEZ-COSTA, Pilar y HERRERA, Susana: La crónica radiofónica. Fragua, Madrid, 2008.

MERAYO, Arturo: La radio en Iberoamérica. Evolución, diagnóstico y prospectiva. Comunicación Social, Sevilla, 2007.

MUNSÓ, Joan: Tiempo de radio. La Esfera Libros, Barcelona, 2006.

ORTIZ, Miguel Ángel: Claves para elaborar la información en radio y televisión. IORTV, Madrid, 2008.

RODRÍGUEZ, Rodrigo Fidel: Radio e información: elementos para el análisis de los mensajes radiofónicos. Universidad de La Laguna, Tenerife, 2006.

SÁNCHEZ, Manuel: Sonido envolvente 5.1.: Una posible solución a la crisis publicitaria radiofónica en España. Dykinson, Madrid, 2008.

SUÁREZ, Michel D.: Dramaturgia audiovisual. Guión y estructuras de informativos en radio y televisión. Comunicación Social, Sevilla, 2007.

TENORIO, Iván: La nueva radio: manual completo del radiofonista moderno. Marcombo, Barcelona, 2008.

VVAA: Los mitos de la publicidad radiofónica: estrategias de la comunicación publicitaria en la radio española. Cátedra, Madrid, 2006. 


\subsection{Otras referencias}

ALCUDIA, Mario: "Misión de los boletines horarios en la radio generalista", Actas do Congreso Internacional Lusocom 2006, Santiago de Compostela, 21 e 22 de abril de 2006.

ALONSO ERAUSQUIN. M.: "Rápido recorrido sobre nuestra limitada bibliografía radiofónica”, Telos. Cuadernos de Comunicación, Tecnología y Sociedad, no 42, junioagosto de 1995.

ARIAS, Elisa: "El serial radiofónico como producto de creación: análisis de la estructura del primer capítulo de "Ama Rosa", Congreso Internacional Investigar la Comunicación, Santiago de Compostela, enero de 2008.

ARIAS, Elisa: “Análisis del lenguaje radiofónico en La saga de los Porretas”, I Jornadas Internacionales de Narrativa Radiofónica, Universidad Complutense de Madrid, Madrid, mayo de 2008.

COMAS, Eva: "Els recursos sonors en els informatius radiofònics. Anàlisi dels recursos sonors en els relats periodístics dels informatius de migdia de Catalunya Informació, Catalunya Ràdio, COM Ràdio, COPE Catalunya, Ona Catalana, Onda Rambla, Ràdio 4 i SER Catalunya del 16 i 17 de juliol del 2001 i del 5 i 6 d'abril de 2004”, Tesis doctoral, Universidad Ramón Llull, Barcelona, 2007.

FERNÁNDEZ, David y BONET, Montse: "Más allá del DAB: otra radio digital es posible", Congreso Internacional ECREA, Barcelona, noviembre de 2008.

GARCÍA, Francisco: "Las ciencias de la comunicación y las ciencias de la Unesco", $V$ Jornadas Internacionales de Investigación en Comunicación, Valencia, 1999.

GARCÍA, Aurora y ROMÁN, Mercedes: "10 años de investigación en radio desde la Universidad de Vigo. De lo local a lo universal", en Congreso Internacional Investigar la Comunicación, Santiago de Compostela, enero de 2008.

GÉRTRUDIX, Manuel y GÉRTRUDIX, Felipe: "RadioNet 2.0: penetración de los servicios de radio online en España", Congreso Internacional ECREA, Barcelona, noviembre de 2008.

GUTIÉRREZ, María: "La singularidad frente a la homogeneidad en la radio convencional española. Las cadenas de ámbito de difusión estatal”, Congreso Internacional Investigar la Comunicación, Santiago de Compostela, enero de 2008. 
GUTIÉRREZ, Arantza: “Las emisoras libres, asociativas y comunitarias del País Vasco en el dial de Internet. Las nuevas tecnologías al servicio de un espacio radiofónico sin cadenas", Congreso Internacional Investigar la Comunicación, Santiago de Compostela, enero de 2008.

HAYE, Ricardo: "La radio y los movimientos artísticos. De la dictadura de la realidad al debilitamiento expresivo", Telos, Cuadernos de Comunicación, Tecnología y Sociedad, $\mathrm{n}^{\mathrm{o}}$ 70, 2007, pp. 23-27.

HERRERA, Susana y PÉREZ, Crisanto: "La duración como dimensión temporal en los reportajes radiofónicos", Área Abierta, nº 18, 2007.

HERRERA, Susana: "Las cualidades del buen creador de reportajes en radio", RePresentaciones, $\mathrm{n}^{\mathrm{o}}$ 2, 2006, pp. 81-101.

HERRERA, Susana: "La estructura del reportaje en radio", Área Abierta, n 17, 2007.

HERRERA, Susana: "La radio española y su apuesta por las nuevas modalidades para la participación de los oyentes", Congreso La ética y el derecho de la información en los tiempos del postperiodismo, Valencia, 2007, pp. 283-306.

HERRERA, Susana: y REQUEJO, José Luis: "Incluyendo recursos de participación Web 2.0 en los portales de radio españoles", Congreso Internacional ECREA, Barcelona, noviembre de 2008.

HURTADO, Carlos: "En busca de la nueva radio", Revista del CES Felipe II, n7, 2007. JONES, Daniel: "La comunicación en el escaparate", Medios de comunicación. Tendencias, $\mathrm{n}^{\mathrm{0}} 6$, http://www.infoamerica.org/TENDENCIAS/tendencias/tendencias06/pdfs/45.pdf LÓPEZ, Mónica: “La radio por Internet: una radio sin fronteras”, Revista Razón y Palabra, $\mathrm{n}^{\circ}$ 49, 2006.

MARTÍ, Josep María: "Factores que inciden en las transformaciones de la radio especializada en el actual contexto digital. Del modelo Radio 1.0 al 2.0", Congreso Internacional Investigar la Comunicación, Santiago de Compostela, enero de 2008. MARTÍ, Josep María y MONCLÚS, Belén: "La construcción de la radio musical 2.0 dentro de la web. Los adolescentes están transformando el formato de música convencional en radio", Congreso Internacional ECREA, Barcelona, noviembre de 2008 . 
MARTÍNEZ-COSTA, Pilar y HERRERA, Susana: "Rasgos diferenciales de la crónica radiofónica", Comunicación y Pluralismo, nº 3, 2007, pp. 11-40.

MARTÍNEZ-COSTA, Pilar y HERRERA, Susana "La crónica radiofónica: entre las rutinas profesionales y la calidad informativa", Comunicación y Hombre, no 3, 2007, pp. 69-80.

MARTÍNEZ-COSTA, Pilar y HERRERA, Susana: "La tertulia radiofónica como un tipo de conversación coloquial”, Doxa Comunicación, nº 5, 2008, pp. 189-211.

MARTÍNEZ-COSTA, Pilar y HERRERA, Susana: "Radiografía del prime time informativo de la radio española”, Comunicación, no 5, 2007, pp. 405-414.

MARTÍNEZ-COSTA, Pilar y HERRERA, Susana: "La participación de los oyentes en la programación de la radio española: estudio del caso de RNE, Radio1", Comunicación y Sociedad, vol. 20, $\mathrm{n}^{\circ} 1,2007$, pp. 29-50.

MARTÍNEZ-COSTA, Pilar; AMOEDO, Avelino y MORENO, Elsa: “Estrategias de comunicación de las cadenas generalistas españolas en la red: anàlisis comparativo de www.cadenaser.com, www.cope.es, www.ondacero.es, www.puntoradio.com y www.rne.es/programas/radiouno en las temporadas 2006-07 y 2007-08", Congreso Internacional Investigar la Comunicación, Santiago de Compostela, enero de 2008.

MATA, Cristina: “Saber sobre la radio", Revista Signo y Pensamiento, n 33, 1998, pp. 91-98.

MORENO, Elsa; AMOEDO, Avelino y MARTÍNEZ-COSTA, Pilar: "Radio y web: estrategias de comunicación de las emisoras de radio españolas en la web (2006-2008)", Congreso Internacional ECREA, Barcelona, noviembre de 2008.

PÉREZ, Aurora; TAMARIT, Ana y RODERO, Emma: “Los géneros radiofónicos empleados en los programas informativos de la Cadena Ser durante los atentados terroristas del 11 de marzo en Madrid (desde el 11 al 14 de marzo de 2004)", X Foro Universitario de Investigación en Comunicación La comunicación: Memoria, Historia y Modelos, Universidad Complutense de Madrid, Madrid, noviembre de 2008.

RODERO, Emma y SÁNCHEZ, Chelo: "Radiografía de la radio en España”, Revista Latina de Comunicación Social, $\mathrm{n}^{\mathrm{o}}$ 62, 2007.

RODERO, Emma: "Caracterización de una correcta locución en los medios audiovisuales", Estudios del Mensaje Periodístico, no 13, pp. 523-542. 
RODERO, Emma: "Punto de escucha en una ficción radiofónica: el eterno problema", Congreso Internacional ECREA, Barcelona, noviembre de 2008.

RODERO, Emma: "Publicidad sí, pero no radiofónica”, Área Abierta, no 20, 2008.

RODERO, Emma: "Educar a través de la radio", Signo y Pensamiento, no 52, 2008, pp. 97-109.

SÁNCHEZ, Chelo y PÉREZ, Aurora: "Busquemos el flautista de Hamelín que devuelva la radio a los niños", XXIII Congreso Internacional Comunicación: Excelencia e Innovación en la Comunicación, Facultad de Comunicación, Pamplona, febrero de 2009.

SEBASTIÁN, Ana y RODRIGO, Luis: "La radio y su publicidad. Creación, estructura y formatos de la cuña radiofónica”, Congreso Internacional Investigar la Comunicación, Santiago de Compostela, enero de 2008.

SOENGAS, Xosé: "El discurso radiofónico. Particularidades de la narración sonora", Revista Prisma, octubre de 2006, pp. 101-127.

TAMARIT, Ana; RODERO, Emma y PÉREZ, Aurora: "El tratamiento de las fuentes en el discurso informativo de la Cadena Ser durante los atentados terroristas del 11 de marzo en Madrid (desde el 11 al 14 de marzo)", Congreso Internacional Investigar la Comunicación, Santiago de Compostela, enero de 2008.

TORAL, G: "Préparer les voix du futur", Médiatiques. Recit et Societé, n 40, Louvain La Neuve, 2007, pp. 8-10.

TORAL, G., MURELAGA, J., VIDALES, N: "Comunicación emocional y miedo escénico en radio y televisión”, Signo y Pensamiento, no 52, 2008, pp. 135- 144.

TORAL, G., MURELAGA, J. VIDALES, N: "Norberarenganako konfiantza eta beldur eszenikoa irrati eta telebistan" ("Autoconfianza y miedo escénico en radio y televisión"), Uztaro, 2007, pp. 65-75.

VENTÍN, Gemma: "La primera novela escrita para la radio: enero de 1926”, Congreso Internacional Investigar la Comunicación, Santiago de Compostela, enero de 2008. 